\title{
Assessment of Magnitude of Hand Washing Practice and Its Determinant Factors among Mothers/ Caretakers in Aman Sub-City, Bench Maji Zone, Southwest Ethiopia, 2017
}

\author{
Asrat Meleko* and Asrat Elias \\ Department of Public Health, Mizan-Tepi University, Ethiopia
}

Submission: January 16, 2018; Published: February 26, 2018

*Corresponding author: Asrat Meleko, Department of Public Health, Collage of Medicine and Health Sciences, Mizan-Tepi University, Mizan Teferi, Ethiopia, Tel: +251-941-9897-97; Email: melekoasrat@gmail.com

\begin{abstract}
Back ground: Due to its tremendous contribution in preventing and controlling most infectious diseases, promotion of appropriate hand hygiene practice has been recognized as an important public health measure. However, globally infectious diseases remain the leading causes of child hood mortality and morbidity accounting for $65 \%$ of all deaths in under-five children which can be prevented if proper sanitation and hygiene measure undertaken. Despite the unquestionable evidence in favor of hand washing, it is observed that young children and their mothers in developing countries fail to practice this habit at critical times.
\end{abstract}

Objectives: To assess magnitude of hand washing practice and its determinant factors among mothers/caretakers in Aman Sub-City, Bench Maji Zone, South -west Ethiopia.

Methods and Materials: Descriptive community based cross sectional study was conducted among Mizan-Aman, Aman sub-city mothers/ caretakers from May to August, 2017. A questionnaire was used to assess the practice of hand washing. Data was analyzed using SPSS software. Bivariate and multivariate analyses were conducted in-order to check the presence of associations between dependent and independent variables.

Result and discussion: A total of 422 mothers/care takers were participated in this study. According to the finding of this study majority, 408 (96.7\%), of mothers/care takers heard about hand washing practice at least once in their life time. Only 164 (38.9\%) of interviewed mothers/ caregivers agreed that they should wash their hand after any contact with other things while the rest. Half 218 (51.7\%) of the respondents believe that they should not wash their hands always using soap. Majority, 374 (88.6\%), of respondents used soap frequently while washing their hands. About 125 (29.6\%) does not care whether they wash their inter digital area and fingernails. According to the multivariate logistic regression result only educational status of mothers/caretakers showed a significant association with hand washing practice.

Conclusion and recommendation: The overall score revealed that significant proportion of mothers had a good knowledge of proper hand washing. However; the translation of knowledge into sustainable behavior needs to be reinforced because only one third of mothers/ caretakers practiced proper hand washing properly. Thus behavioral intervention programs aimed to improve hand hygiene practices should be undertaken intensively by various stakeholders including health care facilities.

Keywords: Hand washing practice; Mothers/caretakers; Mizan Aman; Ethiopia

Abbreviations: CDC: Centre of Disease Control; ARIs: Acute Respiratory Infections; SNNPR: South Nations Nationalities and People Region; SRS: Simple Random Sampling; WHO: World Health Organization

\section{Introduction}

Due to its tremendous contribution in preventing and controlling most infectious diseases, promotion of appropriate hand hygiene practice has been recognized as an important public health measure. It is also acknowledged to be the most appropriate, effective and cost effective way of preventive different types of communicable diseases. And hence the main purpose of proper hand washing is preventing infectious diseases including food borne, water born and feco-orally transmitted diseases which are more of attributed to improper hand washing practice [1]. Hand washing is defined as the vigorous, brief rubbing together of all surfaces of lathered hands, followed by rinsing under a stream of water. Hand washing suspends microorganisms and mechanically removes them by 
rinsing with water. The fundamental principle of hand washing is removal, not killing. It is also a general term applied to either hand washing, antiseptic hand wash, alcohol-based hand rub, or surgical hand hygiene/antisepsis. Until now, hand washing with soap and water remains a sensible strategy for hand hygiene in non-healthcare settings and is recommended by Centre of Disease Control (CDC) and other experts to minimize the burden of infectious diseases [2].

The contribution of proper hand washing practice at critical events is responsible for reduction of infectious disease. However, globally infectious diseases remain the leading causes of child hood mortality and morbidity accounting for $65 \%$ of all deaths in under-five children which can be prevented if proper sanitation and hygiene measure undertaken. Pneumonia and diarrhoea accounts for a 3rd rank of all deaths. In 2012 alone, 502 000 diarrhea deaths were estimated to be caused by inadequate drinking water and 280000 deaths by inadequate sanitation. The most likely estimate of disease burden from inadequate hand hygiene amounts to 297000 deaths. Also various studies confirmed that washing of hands with soap at critical events which includes after using toilet, before handling food and others have reduced infections like diarrhoea, ARI, as well as skin, eyes and helminthes infestations in children [3].

It is confirmed that washing hands with soap after using the toilet or cleaning a child and before handling food can reduce rates of diarrheal disease, including some of its more severe manifestations, such as cholera and dysentery, by 4859 percent. In addition to its tremendous effect to protect health hand-washing with soap is a life-saving intervention within the technological and financial reach of all countries and communities. Research shows that a \$3.35 investment in handwashing brings the same health benefits as an $\$ 11.00$ investment in latrine construction, a $\$ 200.00$ investment in household water supply and an investment of thousands of dollars in immunization. Nonetheless, regardless of its lifesaving potential, hand-washing with soap during the critical time is practiced rarely. Around the world, the observed rates of hand-washing with soap at critical moments range from zero percent to 34 percent [4].

Despite the unquestionable evidence in favour of hand washing, it is observed that young children and their mothers in developing countries fail to practice this habit at critical times [5]. For instance a study conducted in Tanzania found that hands and water are important sources of both viral and bacterial pathogens that cause diarrhea. This finding underscores the importance of efforts to promote hand washing [6]. In Nigeria, the commonest causes of morbidity among children under five years of age are malaria, measles, malnutrition, acute respiratory infections (ARIs) and diarrheal disease. Diarrheal disease and ARIs are strongly linked with poor hand washing practices among other factors [7].
In Ethiopia Diarrhoea is one of the major contributors to deaths for under age 5 children. Based on the WHO/CHERG estimates, diarrhoea contributes to more than one in every ten (13\%) child deaths in Ethiopia. According to EDHS 2016 Mothers reported that $12 \%$ of children under age 5 had a diarrheal episode in the 2 weeks before the survey. It has reported that the prevalence of diarrhoea is slightly higher for children in households with unimproved sanitation than for children in households with improved sanitation including hand washing practice. Additionally, mother's/caretakers educational level was identified as a determinant factor for the prevalence of diarrhea. Also interviewers were able to see a place for hand washing in $60 \%$ of households. Soap and water, the essential hand washing agents, were observed in only $28 \%$ of urban households and $7 \%$ of rural households. Water, soap, and other cleaning agents were absent in $43 \%$ of urban households and $68 \%$ of rural households [8].

Proper hand washing is an easy, less coasty and none time consuming, effective way of preventing many infectious disease and thus it is one way of decreasing infant mortality and morbidity. Data related with magnitude of hand-washing practice and its determinants is very crucial to design appropriate strategy. However, here in the study area there was scarcity of data reviling the sanitation condition of household's especially hand-washing practice of mothers/caretakers and its determining factors. Thus this study was intended to assess Magnitude of hand washing practice and its determinant factors among mothers/caretakers in Aman Sub-City. The findings would be used as a base line data for the next researches. Also the findings could be helpful to implement problem solving strategies towards hand washing related problems.

\section{Objectives}

\section{General objective}

o To assess the magnitude of hand washing practice and its determinant factors among mothers/caretakers in MizanAman, Aman Sub-city, SWE.

\section{Specific objectives}

o To determine the level of practice of hand washing among mothers/caretakers in Aman sub city, Bench Maji zone, SWE

o To assess factors affecting hand washing practice of mothers/caretakers in Aman sub city, Bench Maji zone, SWE

\section{Methods and Materials}

\section{Study area and period}

The study was conducted in Mizan Aman city administration from May to August, 2017. Mizan-Aman town is the capital city of Bench Maji zone, South Nations Nationalities and People Region (SNNPR), and it is located $561 \mathrm{~km}$ far away from Addis 
Ababa. Aman Sub-city has 5 Kebeles (smallest administrative units) and 10 sub Kebeles. According to the statistics from town administration the total population is 34,080 which comprises18138 men and 15,942 women.

\section{Study design}

The study design was community based cross sectional study.

\section{Population}

Source population: Source population was all mothers who live in, Aman Sub-city administration

Study population: Study population was a sample of all mothers/caretakers who live in the randomly selected Kebele.

\section{Sample size determination and sampling technique}

Sample size determination: Sample size for the population based survey was determined using single population

\section{Proportion formula:}

Where,

$$
=\frac{\left(Z_{\alpha / 2}\right)^{2} p(1-p)}{d^{2}}
$$

$d=$ Degree of precision or margin of error $(0.05)$

$\alpha=$ the risk of rejecting the null hypothesis (0.05)

$\mathrm{P}=$ Performance of hand washing (50\%)

$Z=$ the standard score corresponding to $95 \%$ confidence interval.

$$
\begin{gathered}
n=\frac{\left(Z_{0.05 / 2}\right)^{2} 0.5(1-0.5)}{(0.05)^{2}} \\
=\frac{(1.96)^{2} * 0.5-0.5}{0.0025} \approx 384
\end{gathered}
$$

The sample was 384. After, considering $10 \%$ non-response rate, the final sample was settled at 422

\section{Sampling procedure}

From list of three Kebeles one Kebele was randomly selected. The total sample was allocated for selected Kebele. A list of households was obtained from selected Kebele through oncho village registration books and a sample of households was selected from the list of households from selected Kebeles using Simple Random Sampling (SRS) technique. Then after, a list of mothers was obtained from each selected households through oncho village registration books. And one mother/caretaker was selected from the list of mother from each selected households using Systematic Random Sampling technique such that samples of selected 422 mothers/caretakers comprised study subjects.

\section{Inclusion and exclusion criteria}

\section{Inclusion criteria}

o A mother/caretakers who had at list one child alive. o A mother/caretaker who had raising a child/children as adoption.

\section{Exclusion criteria}

o A mother who did not give care for their child/children

o A mother who was unable to participate

\section{Data collection tools and procedures}

Standard questionnaire was adopted from world health organization (WHO). Interviewer administered structured questionnaire was used for data collection among selected persons through survey. The main themes of the questionnaire were demographic data; knowledge and practice of mothers. Data collection was conducted by graduate class students of collage of health sciences in Mizan Tepi University.

\section{Study variables}

Dependent variable: Hand washing practice

Independent variables
$\begin{array}{cl}\text { o } & \text { Knowledge and Practice of hand washing } \\ \text { o } & \text { Socioeconomic status } \\ \text { o } & \text { Educational status } \\ \text { o } & \text { Occupation }\end{array}$

\section{Data quality management}

The collected questionnaires were submitted and edited on daily bases; immediate feedback was given for the problems. The interviewer administered structured questionnaire was translated into Amharic and was pre-tested before data collection. The logical sequence of the questionnaire and the appropriateness of questions, the wording and clarity of language were checked after pre-test. And data collection tools were modified according to the pre-test findings.

\section{Data analysis}

All questionnaires were first checked for accuracy, cleaned manually, coded and then data were entered, edited and analyzed using Epi-Data and SPSS software. Bivariate and multivariate analyses were conducted in-order to check the presence of associations between dependent and independent variables. Finally data was presented using appropriate methods.

\section{Operational definitions}

Proper hand washing: Removing dirties from the nails, between fingers and the visible surface of the hand by using water, soap or any other solutions before and after the recommended activities for the recommended length of time.

Good knowledge: if respondents scores 3 out of 5 knowledge related questions and above. 


\section{Global Journal of Reproductive Medicine}

Good practice: respondents scores 3 out of 5 practice related questions and above Mother/caretakers: woman who have given birth or give care for child.

Ethical issues: Ethical clearance for the research was obtained from Mizan-Tepi University, College of Health Science. Permission letter was sought from Mizan-Aman, Aman sub-city administration office. An informed verbal consent was obtained from every study subject before interview.

\section{Dissemination plan}

The final research report was presented to department of public health, collage of health sciences, Mizan Tepi University. Hard and electronic copies of the final report were disseminated to stakeholders and Mizan Tepi University.

\section{Results}

A total of 422 mothers/care takers were participated in this study. Fortunately, due to commitment of data collectors as well availability of study participants during data collection time the non response rate was $0 \%$. Majority, 202 (47.9\%) of mothers were aged above 30 years old. Married mothers account the largest proportion from the total participants which were 319 (75.6\%). Near to half, $186(44.1 \%)$ of them were housewife and $204(48.3 \%), 170(40.3 \%)$ of them were followers of protestant and Orthodox religion respectively. Most 159 (37.7\%) of interviewed mothers were illiterate and about 185 (43.8\%) of them had average monthly income of 1001 to 2000 Ethiopian birr (Table 1). Knowledge, attitude and practice of mothers/care takers towards hand washing

Table 1: Socio economic characteristics of mothers/care takers in Aman sub city, Bench Maji zone, SWE, 2017.

\begin{tabular}{|c|c|c|c|}
\hline Variable & Category & Frequency & Percent (\%) \\
\hline \multirow{4}{*}{ Age } & $\leq 20$ & 26 & 6.2 \\
\hline & $21-25$ & 40 & 9.5 \\
\hline & $26-30$ & 154 & 36.5 \\
\hline & $\geq 30$ & 202 & 47.9 \\
\hline \multirow{3}{*}{ Marital status } & Single & 55 & 13 \\
\hline & Married & 319 & 75.6 \\
\hline & Divorced & 48 & 11.4 \\
\hline \multirow{8}{*}{ Occupation status of mothers/care takers } & House wife & 186 & 44.1 \\
\hline & Government employee & 35 & 8.3 \\
\hline & Daily laborer & 14 & 3.3 \\
\hline & Merchant & 120 & 28.4 \\
\hline & Student & 20 & 4.7 \\
\hline & Unemployed & 7 & 1.7 \\
\hline & Farmer & 33 & 7.8 \\
\hline & Barberry worker & 7 & 1.7 \\
\hline \multirow{4}{*}{ Religion } & Orthodox Christian & 170 & 40.3 \\
\hline & Protestant & 204 & 48.3 \\
\hline & Muslim & 41 & 9.7 \\
\hline & Others & 7 & 1.7 \\
\hline \multirow{5}{*}{ Educational status } & Illiterate & 159 & 37.7 \\
\hline & Only can read and write & 128 & 30.3 \\
\hline & $1-6^{\text {th }}$ grade & 33 & 7.8 \\
\hline & $7-12^{\text {th }}$ grade & 67 & 15.9 \\
\hline & 12 th grade and above & 35 & 8.3 \\
\hline \multirow{4}{*}{ Monthly income } & $501-1000$ & 139 & 32.9 \\
\hline & $1001-2000$ & 185 & 43.8 \\
\hline & $2001-3000$ & 66 & 15.6 \\
\hline & $\geq 3001$ & 32 & 7.6 \\
\hline
\end{tabular}

\section{Knowledge of respondents about hand washing}

According to the finding of this study majority, 408 (96.7\%), of mothers/care takers heard about hand washing practice at least once in their life time. Role of hand wash was familiar with most interviewed women's which accounted about 375 (88.9\%). Also small number of respondents replied as they consider their hands clean if any visible dirt was absent while the rest majority, 


\section{Global Journal of Reproductive Medicine}

$340(80.6 \%)$ of them replied as might not be clean even in the absence of visible dirt. Majority, 416 (98.6\%) of respondents replied as they wash hands frequently. Regarding to alternative detergents significant number, 100 (23.7\%), of mothers replied as they did not know any other alternative detergents except soap (Table 2). Moreover interviewed mothers in this study Table 2: Knowledge of mothers/care takers about hand washing in Aman sub city, Bench Maji zone, SWE, 2017.

\begin{tabular}{|c|c|c|c|}
\hline Variable & Category & Frequency & Percent (\%) \\
\hline \multirow{2}{*}{ Ever heard about hand washing } & Yes & 408 & 96.7 \\
\hline & No & 14 & 3.3 \\
\hline \multirow{2}{*}{ Know the role of hand washing } & Yes & 375 & 88.9 \\
\hline & No & 47 & 11.1 \\
\hline \multirow{2}{*}{$\begin{array}{c}\text { Think hands as clean when there } \\
\text { is no visible dirt }\end{array}$} & Yes & 82 & 19.4 \\
\hline & No & 340 & 80.6 \\
\hline \multirow{2}{*}{$\begin{array}{c}\text { Do you wash your hands } \\
\text { frequently with soap or other } \\
\text { detergents in the appropriate time }\end{array}$} & Yes & 416 & 98.6 \\
\hline & No & 6 & 1.4 \\
\hline \multirow{2}{*}{$\begin{array}{l}\text { Do you know ash, mud, or/and } \\
\text { sand can } \\
\text { replace soap if not available }\end{array}$} & Yes & 322 & 76.3 \\
\hline & No & 100 & 23.7 \\
\hline
\end{tabular}

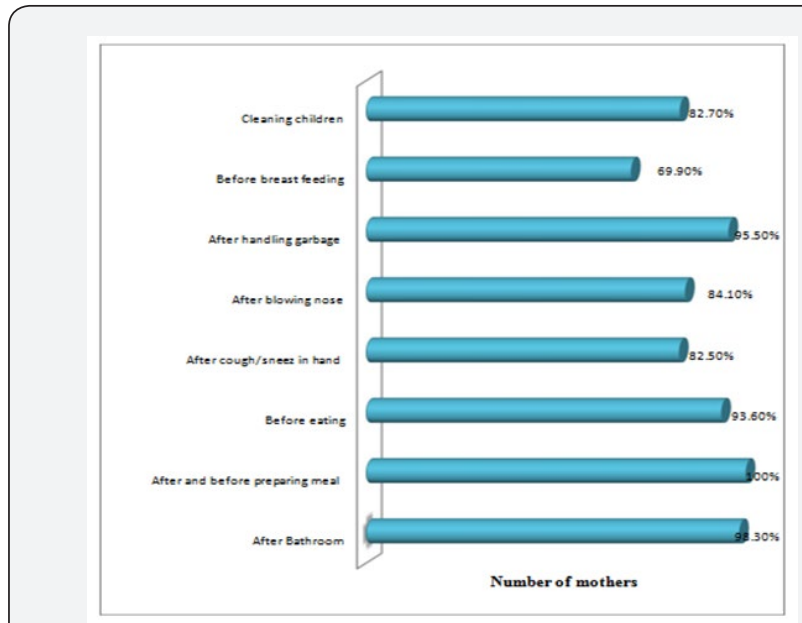

Figure 1: Mothers response towards conditions they wash hands, in Aman sub city, Bench Maji zone, SWE, 2017. area are aware that they should always wash their hand where $100 \%, 98 \%, 93.6 \%, 95.5 \%$ of them in different conditions which includes before and after cooking, after using bath and toilet, before eating, after handling garbage respectively. And only $69.9 \%$ of them knew that they should wash their hand before breast feeding (Figure 1).

\section{Attitude of respondents towards hand washing}

Only 164 (38.9\%) of interviewed mothers/caregivers agreed that they should wash their hand after any contact with other things while the rest $258(61.1 \%)$ of them did not. Moreover $218(51.7 \%)$ of the respondents believe that they should not wash their hands always using soap. Furthermore, majority 374 $(88.6 \%)$ of them had an attitude of hand washing can prevent from diarrhea and other related communicable diseases. About $382(90.5 \%)$ of mothers/care takers also believe that child feces can be cause of different communicable diseases (Table 3). Majority, 374 (88.6\%), of respondents used soap frequently while washing their hands. But only $62(14.7 \%)$ of respondents used ash or mud to replace soap. Meanwhile 125 (29.6\%) does not care whether they wash their inter digital area and fingernails. Also only 144 (34.1\%) of mothers/caregivers dry their hand with towel or waggling their hand after washing their hands (Table 4).

Table 3: Attitude of mothers/care takers towards hand washing in Aman sub city, Bench Maji zone, SWE, 2017.

\begin{tabular}{|c|c|c|c|}
\hline Variable & Category & Frequency & Percent (\%) \\
\hline \multirow{2}{*}{ Do you think you should wash your hands at any contact } & Yes & 164 & 38.9 \\
\hline & No & 258 & 61.1 \\
\hline \multirow{2}{*}{$\begin{array}{l}\text { You should clean your hand by only water without using } \\
\text { soap }\end{array}$} & Yes & 218 & 51.7 \\
\hline & No & 204 & 48.3 \\
\hline \multirow{2}{*}{ You should not wash your hand with soap always } & Yes & 151 & 35.8 \\
\hline & No & 271 & 64.2 \\
\hline \multirow{2}{*}{$\begin{array}{l}\text { Do you think hand washing can prevent from diarrheal } \\
\text { diseases and related disease }\end{array}$} & Yes & 374 & 88.6 \\
\hline & No & 48 & 11.4 \\
\hline \multirow{2}{*}{ Do you think child feces can cause disease } & Yes & 382 & 90.5 \\
\hline & No & 40 & 9.5 \\
\hline
\end{tabular}


Table 4: Hand washing practice of mothers/caretakers in Aman sub city, Bench Maji zone, SWE, 2017.

\begin{tabular}{|c|c|c|c|}
\hline Variable & Category & Frequency & Percent (\%) \\
\hline \multirow{2}{*}{ Did you use soap when washing your hands? } & Yes & 374 & 88.6 \\
\hline & No & 48 & 11.4 \\
\hline \multirow{2}{*}{ Have you ever used ash/mud to wash your hands } & Yes & 62 & 14.7 \\
\hline & No & 360 & 85.3 \\
\hline \multirow{2}{*}{ When you wash your hand it doesn't matter finger } & Yes & 131 & 31 \\
\hline & No & 291 & 69 \\
\hline \multirow{2}{*}{$\begin{array}{l}\text { Do you think hand washing can prevent from diarrheal } \\
\text { diseases and related disease }\end{array}$} & Yes & 125 & 29.6 \\
\hline & No & 297 & 70.4 \\
\hline \multirow{2}{*}{$\begin{array}{l}\text { Have you ever dry your hand with towel or by wagging your } \\
\text { hand after hand wash }\end{array}$} & Yes & 144 & 34.1 \\
\hline & No & 278 & 65.9 \\
\hline
\end{tabular}

\section{Factors associated with hand washing practice}

According to the multivariate logistic regression result only one variable showed a significant association with hand washing practice of mothers/caretakers. This variable was educational status of mothers/caretakers. Those mothers/caretakers with good educational status were more involved in practicing good hand washing practice (Table 5).

Table 5: Factors associated with hand washing practice among mothers/caretakers in Aman sub city, Bench Maji zone, SWE, 2017.

\begin{tabular}{|c|c|c|c|c|c|}
\hline \multirow{3}{*}{ Variable } & \multirow{3}{*}{ Category } & \multirow{2}{*}{\multicolumn{2}{|c|}{$\begin{array}{c}\text { Hand washing } \\
\text { Practice }\end{array}$}} & \multirow{3}{*}{ Crude Odds Ratio } & \multirow{3}{*}{ Adjusted Odds Ratio } \\
\hline & & & & & \\
\hline & & Good & Poor & & \\
\hline \multirow{2}{*}{ Mothers educational status } & Illiterate & 41 & 118 & 1 & 1 \\
\hline & Literate & 105 & 158 & $0.523(0.339,0.805)$ & $0.102(0.054,0.193)$ \\
\hline \multirow{2}{*}{$\begin{array}{c}\text { Knowledge about the role } \\
\text { of hand washing practice in } \\
\text { preventing disease }\end{array}$} & Yes & 111 & 264 & $0.144(0.072,0.288)$ & $0.185(0.577,2.433)$ \\
\hline & No & 35 & 12 & 1 & 1 \\
\hline
\end{tabular}

\section{Discussion}

The main purpose of washing hands is to cleanse the hands of pathogens and chemicals which can cause personal harm or disease. Hand washing with soap removes transient potentially pathogenic organisms from hands and it is not sufficient to wash hands with only water after critical events like defecation. If individuals wash their hands, they are less likely to transmit pathogens from their hands to their mouths. This mechanism benefits the person washing his/her hands and is not available to children. In this study, $375(88.9 \%)$ of the mothers stated that hand washing is important in prevention of communicable diseases. This result is coherent with a study conducted among mothers of under five children in rural coastal South India, that is $83.41 \%$ mothers stated that hand washing was important in prevention of some or the other communicable diseases [9].

According to the finding of this study majority, 408 (96.7\%), of mothers/care takers heard about hand washing practice at least once in their life time. Also small number of respondents replied as they consider their hands clean if any visible dirt was absent while the rest majority, $340(80.6 \%)$ of them replied as might not be clean even in the absence of visible dirt. Majority, 416 (98.6\%) of respondents replied as they wash hands frequently. Regarding to alternative detergents significant number, 100 (23.7\%), of mothers replied as they did not know any other alternative detergents except soap. This finding take us to conclude as the current awareness of mothers with regard to essence and way of using hand washing practices to control various communicable diseases is magnificent. This finding was higher than a result obtained in Oshogbo, Onus State, Nigeria, which posted that $71 \%$ of the mothers rinse their hands with water only and $27.3 \%$ use soap and water [10]. This finding may be associated with the recent government massive involvement in creating awareness as a tool to control sanitation related diseases. Similarly current accessibility of different Medias could be other significant contributor.

It is found that the less knowledge of mothers/caretakers regarding the crucial moments to wash hand has a negative impact on their practice. Interviewed mothers such as 422 (100\%), 413 (98\%), 392 (93.6\%), 403 (95.5\%) of them in know the crucial times to wash their hand which includes before and after cooking, after using bath and toilet, before eating, after handling garbage respectively. This finding was found to be in a better condition than a result obtained in South India 56.9\% of respondents washed their hands after defecation, and only $21.9 \%$ of them after using toilet for urination [9]. This might be attributed to the current information access of mothers/ 


\section{Global Journal of Reproductive Medicine}

caretakers in different settings including mass medias and different health care facilities.

The CDC recommends rubbing hands should at list take 20 seconds. Wetting, applying soap and rinsing, in general with rubbing should take at least 1 minute. This practice is enough to remove dirty as well as microorganisms, thus preventing infectious diseases. In this study majority, 374(88.6\%), of respondents used soap frequently while washing their hands. But only $62(14.7 \%)$ of respondents used ash or mud to replace soap. Meanwhile 125 (29.6\%) does not care whether they wash their inter digital area and fingernails. Also only 144 (34.1\%) of mothers/caregivers dry their hand with towel or waggling their hand after washing their hands. This finding is coherent with a result obtained in others areas [11].

Only $164(38.9 \%)$ of interviewed mothers/caregivers agreed that they should wash their hand after any contact with other things while the rest $258(61.1 \%)$ of them did not. Moreover $218(51.7 \%)$ of the respondents believe that they should not wash their hands always using soap. This figures revealed that their attitude towards giving attention for hand washing was very minimal. It was coherent with a finding obtained in Ghana [12]. Knowledge and practice questions were summarized together to see the overall finding. Accordingly, majority, 320 (75.8\%) of respondents had good knowledge about hand washing and its importance. However, based on the summation of individual scores only 146 (34.6\%) interviewed mothers/caretakers had a good hand washing practice. This may be attributed their negative attitude towards the tangible effect of proper hand washing practice to control and prevent various communicable diseases. Various researches conducted in different settings identified that there a different types of variables affecting hand washing practice. Accordingly, this study found that only mothers/caretakers education level had a significant association with hand washing practice. This finding was coherent with a similar study conducted in India where mothers/caretakers education level had shown a significant association with hand washing practice [13].

\section{Conclusion and recommendation}

\section{Conclusion}

The overall score revealed that significant proportion of mothers had a good knowledge of proper hand washing 320 (75.8\%). However; the translation of knowledge into sustainable behavior needs to be reinforced because only 146 (34.6\%) of the mothers practiced proper hand washing properly. The finding also identified that respondent's attitude to give more attention towards hand washing practice was not sufficient that much.

\section{Recommendation}

Since sanitation is the pillar in controlling different communicable diseases specially hand washing, it is imperative to made broad intervention in this area. Based on the finding of this study it was recommended for various concerned stakeholders as follows.

o The major problems regarding hand washing practice in most groups whether they are literate or illiterates are changing their knowledge to practice. Thus behavioral intervention programs aimed to improve hand hygiene practices should be undertaken intensively by various stakeholders including health care facilities.

o Researchers should be involved in conducting further researches on the barriers between proper hand washing knowledge and practice.

o Also it could be better to strengthen enabling factors of the community on hand washing facilities (soap, safe water supply)

\section{Acknowledgement}

First of all, we would like to thank Department of public health, collage of health sciences, Mizan Tepi University for allowing us to conduct this research. Also we are grateful to all study participants for their sincere support during data collection.

\section{References}

1. Tao SY, Cheng YL, Lu Y, Hu YH, Chen DF (2013) Hand washing behavior among Chinese adults: a cross-sectional study in five provinces. Public Health 127(7): 620-628.

2. Centers for diseases control and prevention (CDC) (2009) Cfdcap.

3. Centers for diseases control and prevention (CDC) (2016) Global WASH facts.

4. United Nations Children's Fund (UNICEF) (2016). WASH in West and central Africa.

5. Kosek M, Bern C, Guerrant RL (2003) The Global burden of diarrheal disease, as estimated from studies published between 1992 and 2000. Bull World Health Organ 81(3): 197-204.

6. Vujcic J (2012) Periodic overview of hand washing literature: Summary of selected peer-reviewed and grey literature.

7. Aigbiremolen AO, Abejegah C, Ike CG, Momoh JA, Lawal-Luka RK (2015) Knowledge and Practice of Hand Washing among Caregivers of UnderFive Children in a Rural Nigerian Community. Public Health Research 5(5): 159-165.

8. Ethiopian Federal Democratic Republic (2016) Ethiopian Demographic and Health survey (EDHS). Addis Ababa, Ethiopia: Central Statistical Agency, Ethiopia.

9. Datta SS, Singh Z, Boratne AV, Senthilvel V, Bazroy J, et al. (2011) Knowledge and practice of hand washing among mothers of under five children in rural coastal South India. Int J MedPublic health 1(1): 3338.

10. Asekun-Olarinmoye EO, Omobuwa O, Adebimpe WO, AsekunOlarinmoye, Ifeoluwapo O (2014) Hand Washing: Knowledge, Attitude and Practice amongst Mothers of Under-Five Children in Osogbo, Osun State, Nigeria. Journal of Biology Agriculture and Healthcare 4(16).

11. Jaslow R (2013) CBS News.

12. Steiner-Asiedu M, Van-Ess SE, Papoe M, Setorglo J, Asiedu DK, et al. (2011) Hand Washing Practices among School Children in Ghana. Current Research Journal of Social Sciences 3(4): 293-300. 
13. Samreen K, Vishwanath Kr, Neha P, Sachin Singh Y (2017) Handwashing practices among the caregivers of under five children in rural and urban areas of Moradabad, India: a community based study. Int J MedPublic health 6(1): 133-138.

This work is licensed under Creative

Commons Attribution 4.0 License

DOI: 10.19080/GJORM.2018.03.555617

\section{Your next submission with Juniper Publishers will reach you the below assets}

- Quality Editorial service

- Swift Peer Review

- Reprints availability

- E-prints Service

- Manuscript Podcast for convenient understanding

- Global attainment for your research

- Manuscript accessibility in different formats

( Pdf, E-pub, Full Text, Audio)

- Unceasing customer service

Track the below URL for one-step submission https://juniperpublishers.com/online-submission.php 